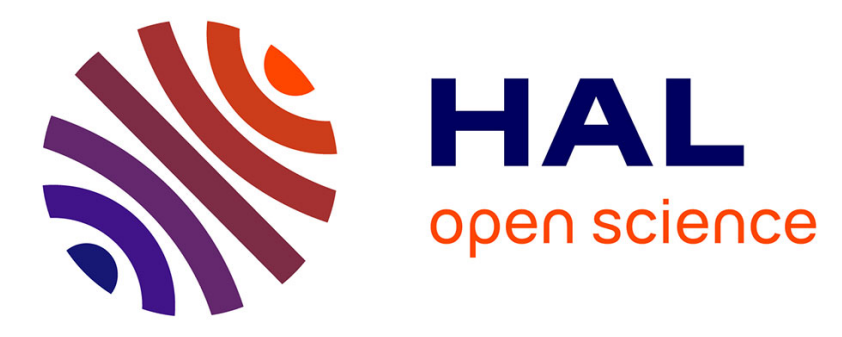

\title{
Discriminating cropping systems and agro-environmental measures by remote sensing
}

José Manuel Peña-Barragán, Francisca López-Granados, Luis García-Torres, Montserrat Jurado-Expósito, Manuel Sánchez de La Orden, Alfonso García-Ferrer

\section{To cite this version:}

José Manuel Peña-Barragán, Francisca López-Granados, Luis García-Torres, Montserrat JuradoExpósito, Manuel Sánchez de La Orden, et al.. Discriminating cropping systems and agroenvironmental measures by remote sensing. Agronomy for Sustainable Development, 2008, 28 (2), pp.355-362. hal-00886388

\section{HAL Id: hal-00886388 https://hal.science/hal-00886388}

Submitted on 1 Jan 2008

HAL is a multi-disciplinary open access archive for the deposit and dissemination of scientific research documents, whether they are published or not. The documents may come from teaching and research institutions in France or abroad, or from public or private research centers.
L'archive ouverte pluridisciplinaire HAL, est destinée au dépôt et à la diffusion de documents scientifiques de niveau recherche, publiés ou non, émanant des établissements d'enseignement et de recherche français ou étrangers, des laboratoires publics ou privés. 


\title{
Discriminating cropping systems and agro-environmental measures by remote sensing
}

\author{
José Manuel PEÑA-BARRAGÁN ${ }^{a} *$, Francisca LÓPEZ-GRANADOS ${ }^{\mathrm{a}}$, Luis GARCÍA-TORRES ${ }^{\mathrm{a}}$, \\ Montserrat JURADO-EXPÓSITO ${ }^{\mathrm{a}}$, Manuel SÁNCHEZ DE LA ORDEN ${ }^{\mathrm{b}}$, Alfonso GARCíA-FERRER ${ }^{\mathrm{b}}$ \\ ${ }^{1}$ Institute for Sustainable Agriculture, CSIC, PO Box 4084, 14080 Córdoba, Spain \\ ${ }^{2}$ Remote Sensing Department, University of Córdoba, PO Box 3048, 14080 Córdoba, Spain
}

(Accepted 20 September 2007)

\begin{abstract}
The agrarian policy of the European Union tends to support sustainable agriculture, subsidising only cropping systems that are implemented with specific agro-environmental measures. These actions require a precise follow-up of the crops and of the agricultural practices over a large surface. To that end, remote-sensing techniques are unique and cost-effective. We developed here a digital land cover classification in the Mediterranean dryland, mapping and assessing the main cropping systems and some agro-environmental measures such as cover crops in olive orchards and crop stubble for reducing soil erosion. We analysed a high spatial resolution satellite image (QuickBird) taken in early summer around Montilla, southern Spain. Images of the four broad wavebands, six band ratios and three vegetation indices were extracted from the satellite image and studied for the discrimination of nine land covers. The classified regions were determined by applying adequate boundary digital values to the selected images. Our results show that the land covers were discriminated with an overall accuracy of about $90 \%$. Images of the normalised difference vegetation index and the ratio vegetation index discriminated between vegetation and non-vegetation zones. The visible wavebands discriminated roadside trees and herbaceous crops, and the near-infrared waveband highways and urban soil plus bare soil. The ratios blue/green and red/green were useful for distinguishing non-burnt stubble. The burnt stubble area was discriminated through the adapted burnt area index. Olive orchards were classified once the regions of vegetation, non-vegetation and non-burnt stubble were extracted. This technology will be a useful tool of agroecology control for the administration and will be a substitute for the current follow-up of cropping systems by ground visits. It can also be used on a farm level in order to help farmers and technicians to make decisions about the management of sustainable agricultural practices.
\end{abstract}

burnt stubble / bare soil / cover crops / crop stubble / land cover classification / no-tillage / olive orchards / QuickBird

\section{INTRODUCTION}

Nowadays, the European Union subsidises most cropping systems and simultaneously requires the implementation of certain agro-environmental measures, such as the non-burning of stubble, cover crops in tree orchards and no-tillage techniques (Anonymous, 2003, 2004). These agrarian policy actions require a precise follow-up of the crops and of certain sustainable agricultural practices in each cultivated plot. Current methods to map agricultural practices consist of driveby, or what is commonly referred to as windshield surveys, to sample fields on a county-by-county basis. The drive-by method consists of designing transects, from which the results are used to estimate or extrapolate the agricultural system used in the entire county (South et al., 2004). In southern Europe, the follow-up of cropping systems by the European Union administrations has been achieved by sampling and ground visits to the selected farms. However, this procedure of vehiclemounted and real-time systems covers relatively small areas and is time-consuming and very expensive compared with remote-sensing systems. Furthermore, on a large scale ground visits are a less reliable methodology than the interpretation

\footnotetext{
* Corresponding author: pa2pebaj@uco.es
}

of remotely-sensed images, since the former does not provide consistent records of land-cover estimation. Digital land cover classification of a remotely-sensed image is an alternative to the ground visits and the visual interpretation and consists of the association of areas fitting some similarity criteria; for example, the similar spectral response pattern across the spectral bands or vegetation indices. The resulting classified image is like a thematic map, in which every class is statistically characterised by very close spectral values. Remotely-sensed data can offer the ability to efficiently identify agricultural cropping practices over large areas. Synoptic remotely-sensed imagery allows the classification of agricultural systems without any need for spatial averaging or the extrapolation of results to completely assess an area (South et al., 2004).

Several classification methods have been used for agricultural land cover classification studies (Oetter et al., 2000; South et al., 2004). Generally, the digital classification process can be unsupervised or supervised. The unsupervised classification process is interpreted by algorithms, which identify the tentative land covers in accordance with the digital values of a wavelength, band or vegetation index. Supervised classification is based on the operator's knowledge of the area to be classified by previously defining a sample of each specific land cover to be detected over the whole image. Other techniques 
are based on the use of object segmentation algorithms and on the construction of a hierarchical network of image objects, and works on the treatment of several data types simultaneously such as pixel values, object features and hierarchical relationships (Baatz and Schäpe, 1999).

Felton et al. (2002), and Thorp and Tian (2004) reviewed the uses of remote sensing in agriculture, and reported that, to date, the majority of studies on discriminating plant species in cultivation systems have involved discrete broadband remote sensing using multispectral sensors. Spectral reflectance differences can be enhanced by using vegetation indices, which are mathematical (ratios or linear) combinations between bands or selected wavelengths. They take advantage of the vegetation reflectance contrast between different wavelengths. Those most widely used in multispectral remote-sensing research for detecting and quantifying vegetation are: the normalised difference vegetation index (NDVI) (Rouse et al., 1973) and the ratio vegetation index (RVI) (Jordan, 1969). The NDVI and RVI are commonly used to differentiate vegetation because it usually shows a high reflectance in the near-infrared spectral band and a low one in the red band, and both indexes enhance these differences (Jackson and Huete, 1991; Elmore et al., 2000). A soil-adjusted vegetation index (SAVI) was proposed by Huete (1988) to minimise the effects of soil background on the quantification of greenness by incorporating a soil adjustment factor (L) into the basic NDVI form. This factor is determined by the relative percentage of vegetation and whether the soil is light or dark; it is used as a multiplier $(\mathrm{L}+$ 1 ) in the first term and is usually defined as 0.5 (Huete et al., 1994). The burnt area index (BAI) was used to discriminate the burnt forest (Chuvieco et al., 2002), and could be useful to determine stubble burning, a traditional practice which will from now on be only exceptionally permitted due to new environmental regulations (Anonymous, 2004).

Many authors have identified and mapped certain plant species using remote images. Casady et al. (2005) mapped Euphorbia esula infestations using multidate high-resolution satellite imagery. Anderson et al. (1993), using multispectral images of the SPOT satellite, characterised the Ericameria austrotexana infestation in a ranch of 4400 has in southern Texas (USA). Oetter et al. (2000) with LANDSAT satellite images of about $28 \mathrm{~km} 2$ of the Willamette river basin (Western Oregon, USA) taken in several seasons in the year, developed several algorithms for an unsupervised classification of 20 soil uses. Keuchel et al. (2003) applied several supervised classification methods to determine soil uses in southern Tenerife (Spain). Underwood et al. (2003) mapped infestations of Carpobrotus edulis and Cortaderia jubata on the southern coast of California using an airborne image of the hyperspectral sensor AVIRIS.

South et al. (2004) examined five classification methods to determine the most suitable classification algorithm to identify no-tillage and traditional tillage cropping methods, concluding that the spectral angle mapper and the cosine of the angle concept were superior to other traditional classification methods. Everingham et al. (2007) have also tested two relatively new classification methods, support vector machines and random forests, using hyperspectral imagery with the objective of classifying sugarcane crop characteristics, demonstrating that hyperspectral remote sensing is a successful technology for sustainable agricultural studies, since it offers high spectral resolution images with very small narrow-bands. However, hyperspectral imagery is not easily available in most regions and is still a very expensive material, so multispectral satellite imagery could be more cost-effective in most cases.

In image processing for land cover classification, to avoid any subjective estimation, a numerical confusion matrix analysis is normally used to quantify the coincidence between created and ground-truth regions (Stehman and Czaplewski, 1998). User accuracy is defined as being the percentage of classified pixels of each land cover that coincide with the verified ground-truth map, and indicates its correct assessment. Overall accuracy indicates the overall success of the classification, and has been standardised at $85 \%$ for the minimum accepted value (Thomlison et al., 1999). Kappa statistics provide a classification accuracy assessment that can arise for random or chance classification. Landis and Kock (1977) suggested that kappa statistics of over $80 \%$ strongly indicate that a given classification was unlikely to have been obtained by chance alone.

Several works have been developed in the Mediterranean area to follow up diverse agricultural topics by remote sensing, such as plant height and biomass and leaf area index (Calera et al., 2002), and monitoring irrigation water (Martin de Santa Olalla et al., 2003). Peña-Barragán et al. (2004) discriminated and assessed cover crops, a key agro-environmental measure, in olive-tree orchards, by selecting the Blue/Red ratio. However, information on automatic digital supervised classification of main land cover / cropping systems and of key agroenvironmental measures in a typical dryland Mediterranean area with a high spatial resolution satellite is lacking, and this was the goal of this work. Specific objectives were: (a) to select vegetation indices for the discrimination of each land cover; and (b) to define image processing sequences to automatically complete each land cover / agro-environmental measurement separation and quantification, and their statistical accuracy.

\section{MATERIALS AND METHODS}

\subsection{Satellite image and land covers}

The study area is located around Montilla, province of Córdoba, southern Spain. It is relatively flat, about $380 \mathrm{~m}$ above sea level; with a typical continental Mediterranean climate, characterised by long dry summers and mild winters. The area was a rectangle of $15.3 \times 5.4 \mathrm{~km}\left(82.62 \mathrm{~km}^{2}\right)$ taken from one QuickBird nominal scene on 10 July 2004 (partial view in Fig. 1a). Its spatial resolution was $0.70 \times 0.70 \mathrm{~m}$ in panchromatic and $2.8 \times 2.8 \mathrm{~m}$ in multispectral (Bands: Blue, 450-520 nm; Green, 520-600 nm; Red, 630-690 nm; and Near-infrared, NIR, 760-900 nm). Radiometric, geometric and georeference corrections were previously carried out.

Nine land-cover classes were considered, as follows: (1) agricultural bare soil, (2) burnt stubble (of winter wheat 
(a)

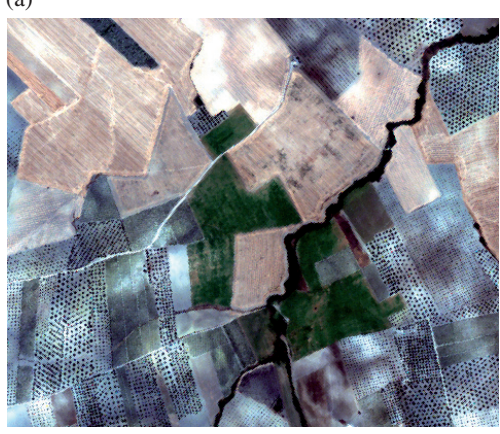

(c)

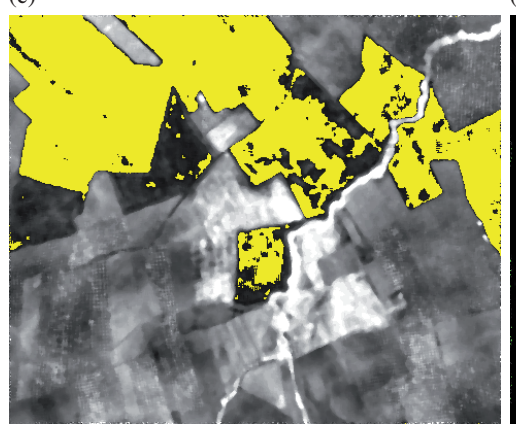

(b)

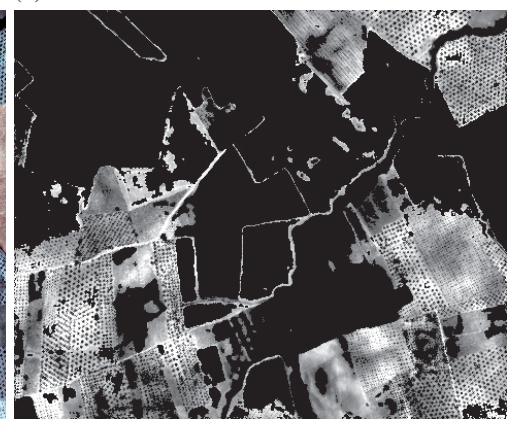

(d)

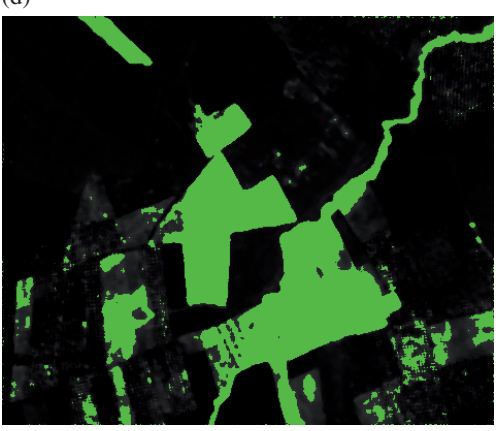

Figure 1. View of 148 ha surface of the QuickBird satellite image taken on 10 July 2004, corresponding to: (a) Conventional-colour composition of the multispectral image, showing typical land covers in the Mediterranean dryland (Montilla, southern Spain) such as olive orchards, wheat stubble, herbaceous crops, vineyards and roadside trees; (b) classified regions corresponding to non-burnt stubble (masked in yellow); (c) classified regions corresponding to herbaceous crops, vineyards and roadside trees (masked in green); and (d) classified regions corresponding to olive orchards (non-masked).

(Triticum durum L.) crops, generally), (3) spring-sown herbaceous crops, such as sunflower (Helianthus annuus L.), (4) highways, (5) olive (Olea europea L.) orchards, (6) roadside trees made up of mulberry-tree (Morus alba L.), eucalyptus (Eucalyptus globules Labill) and poplar (Populus nigra L.), (7) urban soil, (8) vineyards (Vitis vinifera L.), and (9) nonburnt stubble (of winter wheat crops, generally). Ground-truth land cover was randomly defined at mid-spring and early summer and georeferenced through ground visits to substantiate and validate the classification procedure. This consisted of georeferencing around 9 training zones and 9 ground-truth zones of each land-cover class, of about 0.3 ha each for highways and roadside trees, and of 1.5 ha each for the other land covers. Training zones were used to define the boundary digital values to be used in the classification routines. Groundtruth zones were used for classification accuracy assessments (Mckoy, 2005).

\subsection{Vegetation indexes and classification methods}

Every pixel of the studied QuickBird satellite image showed a digital value from 0 to 255 for each waveband, corresponding to 8 bits of radiometric resolution. These digital values were considered as being directly proportional to the total light reflected from the scene (Flowers et al., 2001). Specific classified regions of every individual land cover, or of a group of land covers with similar digital value characteristics, were created for discrimination purposes with the rest of the land covers, similarly to that achieved by other authors (Lamb and Weedon, 1998; Peña-Barragán et al., 2004). A total of thirteen images was extracted from the satellite image and studied for the discrimination of the nine land covers previously indicated, as follows: the four multispectral bands: Blue, Green, Red and NIR; six band ratios: RVI = NIR/Red, Blue/Green, Blue/Red, Red/Green, NIR/Blue, NIR/Green; and three vegetation indexes: NDVI, adapted SAVI (ASAVI), and adapted BAI (ABAI):

$$
\begin{gathered}
N D V I=\frac{N I R-\text { red }}{N I R+\text { red }} \\
A S A V I=\frac{\left(\frac{N I R}{255}\right)-\left(\frac{r e d}{255}\right)}{\left(\frac{N I R}{255}\right)+\left(\frac{r e d}{255}\right)+L} \cdot(1+L) \\
A B A I=\frac{1}{\left[0.1-\left(\frac{r e d}{255}\right)\right]^{2}+\left[0.06-\left(\frac{N I R}{255}\right)\right]^{2}}
\end{gathered}
$$

For each waveband, band ratio and vegetation index, the mean and standard deviation of the digital values of each land cover, and the significant differences between land cover means were also estimated by multiple one-way analysis of variance and Least Significant Difference (LSD) tests at a $P$ of 0.05 .

Boundary digital values were used to define each region in an iterative way, based on the information provided by the ground-truth zones of each land cover, established according to the statistical value obtained from the training pixels, adding and reducing the standard deviation to the average; i.e., if the 
training zone set had a mean digital value of 25 and a standard deviation value of 4 , the boundary digital values could be around 21-29. The boundary digital values selected were the ones that best discriminated the two classified regions, providing a greater statistical accuracy. Every image from the vegetation index, ratio or waveband was classified by grouping the digital value threshold interval that best characterised each land cover (Lamb and Weedon, 1998). A supervised classification method was used to discriminate any specific land cover, or group of land covers, by creating classified regions defined by the boundary digital values in the entire image. In an iterative way, sets of boundary digital values were established for each land cover, or group of land covers, to best discriminate the land cover/s considered from the others. The overall olive orchard cover class was also discriminated by deleting from the entire image the region that resulted from the merging of the three following previously classified regions: vegetation (made up of the spring-sown herbaceous crops plus vineyards plus roadside trees classes), non-vegetation (made up of the agricultural bare soil plus urban soil plus highways classes) and non-burnt stubble. The urban soil class was defined and isolated visually in the multispectral image. The agricultural bare soil class was defined by deleting the urban soil class in the previously defined classified region made up of the agricultural bare soil plus urban soil classes. A median filter $5 \times$ 5 (MF $5 \times 5$ ) was also applied to some selected classified images, such as the images from the NDVI, RVI and Blue/Green, to decrease land cover heterogeneity. The burnt stubble class was estimated with the ABAI. Cover crops inside olive orchards were estimated over the classified olive orchards cover class, applying the NDVI to discriminate the olive trees and the Blue/Red ratio to discriminate cover crops, as suggested by Peña-Barragán et al. (2004). The areas of each classified land cover region were determined.

To avoid any subjective estimation, the discrimination efficiency of each set of boundary digital values was checked through a numerical confusion matrix analysis. The overall accuracy and kappa coefficient of the whole classification process and the user accuracy of each classified land cover ("user accuracy") were also calculated. Generally, regions classified with overall accuracy, kappa coefficient and user accuracy over $90 \%, 85 \%$ and $90 \%$, respectively, were selected to define each land cover or group of land covers. ENVI 4.0 (Research Systems Inc. 2001) was the software used for image processing.

\section{RESULTS AND DISCUSSION}

Mean and standard deviation digital values for each land cover and studied wavebands, ratios and vegetation indices are shown in Table I. Low boundary digital values of the Blue, Green and Red wavebands can be used to discriminate the roadside trees class and/or the spring-sown herbaceous crops class from other land covers; while high boundary digital values of these wavebands could discriminate the urban soil class and/or the non-burnt stubble class. The NIR waveband can be used to discriminate either the highways class or the highways plus urban soil plus agricultural bare soil classes together. The
NDVI and the RVI clearly discriminated vegetation (roadside trees plus spring-sown herbaceous crops and vineyards classes) on one hand, and the absence of vegetation (highways, urban soil and agricultural bare soil classes) on the other. Some ratios such as the Blue/Green and the Red/Green clearly distinguished the non-burnt stubble class from the other land covers.

The agricultural bare soil and urban soil classes exhibited very similar digital values for every vegetation index, but significant differences in the Blue, Green and Red wavebands (Tab. I). In addition, the urban soil class can be visually delimited and discriminated in the multispectral image. The ASAVI (for $\mathrm{L}=0.5$ ) enhances the effect of the NDVI but it was of no use for discriminating between the agricultural bare soil and the urban soil classes. Similarly, at the point where the QuickBird image was taken, both the vineyards and the spring-sown herbaceous crops classes exhibited very similar digital values but field plots of these land covers can be distinguished in the panchromatic image due to the characteristic plant-row spacing of the vineyards class. Also, because of the wide spacing between olive trees, normally $10 \times 10 \mathrm{~m}$, the olive orchards class is a mixture of vegetation and bare soil. As a result, any vegetation index selected for the olive orchards class exhibited intermediate digital values and a greater heterogeneity than that of vegetation and non-vegetation land covers and, therefore, it was hard to directly discriminate it from the remaining land covers using the classification methods based on pixels. To a lesser extent, this was also the case of the vineyards class, since the vines were normally spaced at $1.5 \times 1.5 \mathrm{~m}$ and, in early summer, when the image was taken, the vegetation was at a growing phase, only partially covering the soil. On the other hand, the urban soil class is also a mixture of bare soil with, to a much lesser extent, vegetation, due to ornamental trees and gardens. So, the application of a median filter (kernel $5 \times 5)$ to the NDVI and the RVI and Blue/Green ratio decreased the heterogeneity of the olive orchards class and, to a lesser extent, also of the vineyards and the urban soil classes (data not shown). This transformation hardly affected the mean and standard deviation digital value of the other land covers.

The classified regions of certain land covers and corresponding boundary digital values are shown in Table II. For example, the non-burnt stubble region could be defined with the Blue/Red ratio and boundary digital values of 0.500 to 0.635 and with the Red/Green and boundary digital values of 0.870 to 1.200 , with overall accuracies of $95 \%$ and $96 \%$, respectively (Fig. 1b). The highways and roadside trees classified regions were obtained with the transformation NDVI plus the median filter $(5 \times 5)$, then applying boundary digital values of 0.001 to 0.025 and of 0.451 to 0.700 , with overall accuracies of $99 \%$ and $94 \%$, respectively. The roadside trees class was discriminated with a user accuracy of $100 \%$, but the overall accuracy was $94 \%$ and the kappa coefficient was 0.85 , indicating that this class was slightly overestimated because some ground-truth pixels of the other classes were classified as roadside trees class. The highways class could also be separated with a $99 \%$ overall accuracy using the Blue waveband with boundary digital values of 0.001 to 0.019 . The burnt stubble classified region was discriminated using the ABAI and 


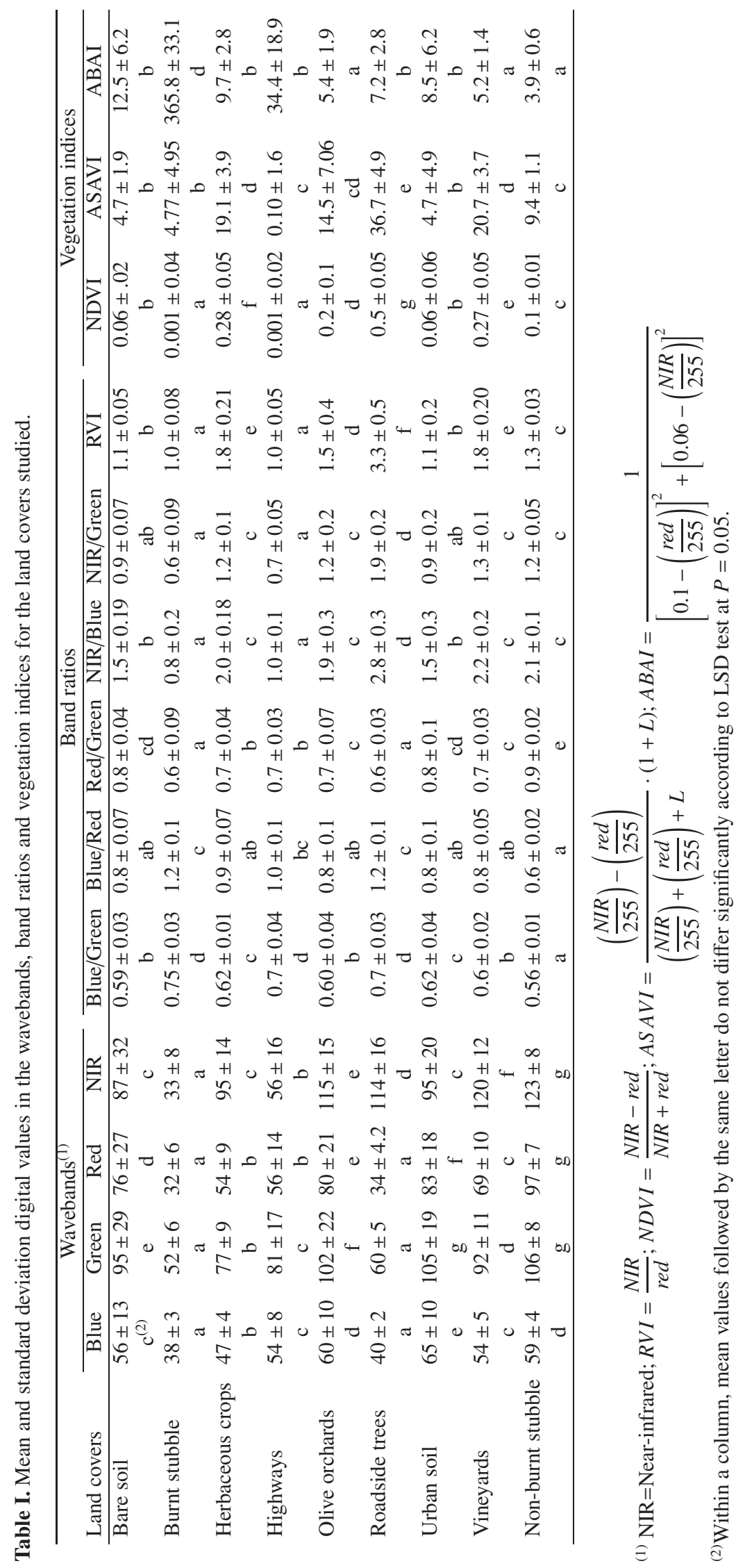




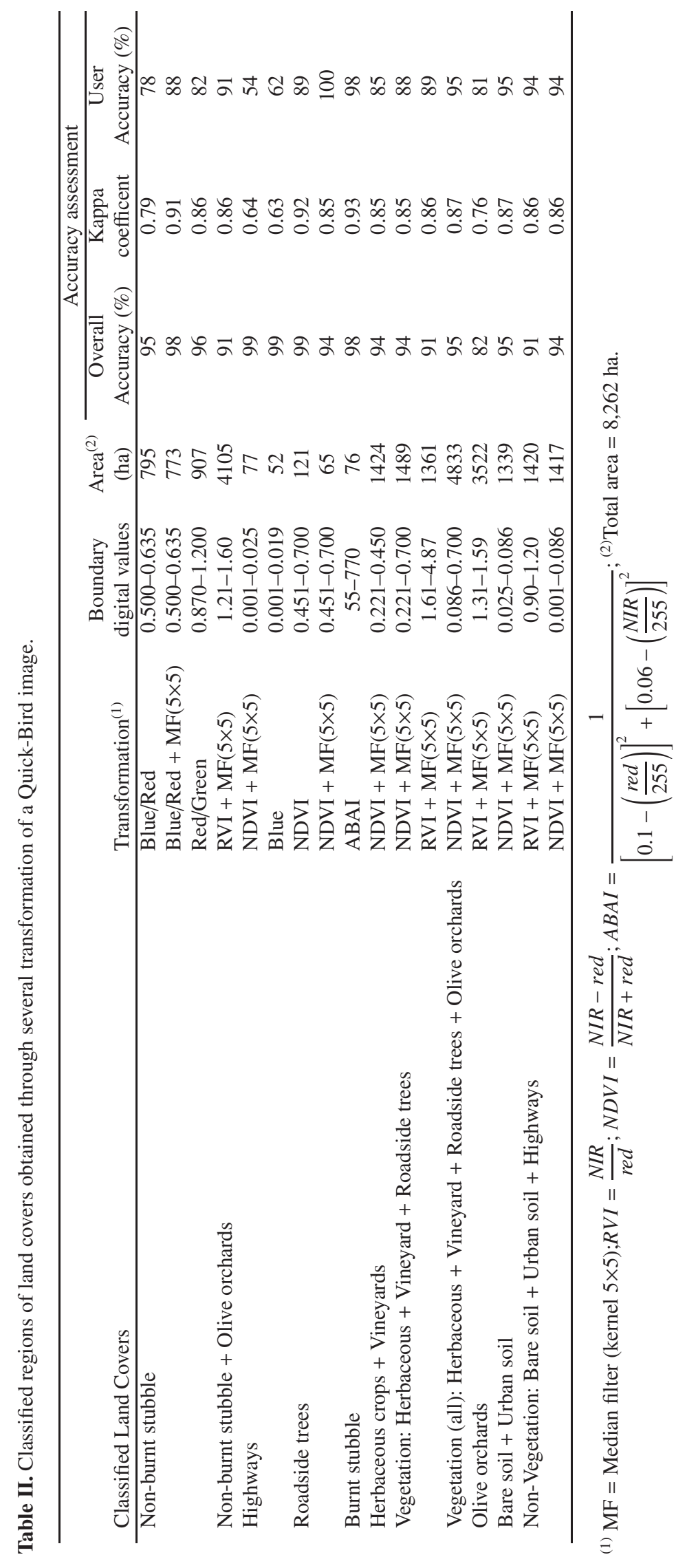


boundary digital values up to 55 , with an overall accuracy of $98 \%$.

The land covers "spring-sown herbaceous crops plus vineyards" and/or "spring-sown herbaceous crops plus vineyards plus roadside trees" were jointly discriminated from the rest of the land covers using the NDVI plus the median filter $(5 \times 5)$ and/or the RVI plus the median filter $(5 \times 5)$, with overall accuracies of about $94 \%$ and $91 \%$, respectively (Tab. II; Fig. 1c). At the point where the QuickBird image was taken, the separation between the spring-sown herbaceous crops and the vineyards classes could not be accomplished through the sole use of vegetation indices due to they have similar digital values. However, the differentiation between the spring-sown herbaceous crops and the vineyards classes could be achieved visually in the panchromatic image, where, due to its higher spatial resolution $(0.7 \times 0.7 \mathrm{~m})$, it was possible to distinguish the characteristic plant/row spacing of vineyards (normally $1.5 \times$ $1 \mathrm{~m}$ ), which was obviously absent in the spring-sown herbaceous crops class. Alternatively, the differentiation between the spring-sown herbaceous crops and the vineyards classes could also be carried out using a QuickBird image taken in mid-late summer, where dryland herbaceous crops such as sunflower were desiccated while the vineyards class still appeared in green.

The olive orchards classified region was obtained using the RVI plus the median filter $(5 \times 5)$ with intermediate overall and user accuracy of about $82 \%$ (Tab. II; Fig. 1d). The olive orchards class was also discriminated with a greater accuracy, an estimated $88 \%$ (data not shown), by deleting the classified vegetation (spring-sown herbaceous crops plus vineyards plus roadside trees classes), non-vegetation (agricultural bare soil plus highways plus urban soil classes) and the non-burnt stubble regions in the entire image, resulting in about 3335 ha. Cover crop area in the olive orchards region, estimated with the Blue/Red ratio and boundary digital values of 0.500 to 0.635 , resulted in 470 ha. The agricultural bare soil plus urban soil classes were jointly defined through processing the NDVI plus the median filter $(5 \times 5)$ at the boundary digital values of 0.025 to 0.086 , and resulted in a surface of 1339 ha and $95 \%$ overall accuracy. The urban soil class was visually defined in the multispectral image, resulting in a total surface of 178 ha. The agricultural bare soil class was defined by deleting the urban soil class in the previously defined classified region (agricultural bare soil plus urban soil).

Discriminations of cropping systems and of agroenvironmental measures are interrelated. However, cropping system classification can be considered as being a preliminary step for agro-environmental measure assessment. For example, if the target is to determine cover crops in olive orchards in a large area, the previous isolation of the olive-orchard land cover is required. Additionally, a good knowledge of the area's agriculture, and particularly of the cropping system phenology and practices, is essential to interpret and establish a feasible methodology of land cover classification by remote sensing.

The same image analysis procedure can be implemented over the entire satellite image of dozens of square kilometres or over any specific farm or single plot. Nevertheless, the assessment of land cover classification on an individual farm or plot basis could be easier and more accurate than on a larger spatial scale, since the interpretation of the inherent heterogeneity of some land covers is easier to recognise and correct by the image interpreter in the former than in the latter. For example, olive-orchard land cover, due to it being made up of a mixture of vegetation (trees) and diverse types of bare soils and cover crops, is very often not fully discriminated by a single image processing. In that case, image processing could be improved by using structure analysis, combining the spectral and spatial features of this land cover, thus increasing the accuracy of the overall classification and the final decision-making. Furthermore, the overall assessment of any land cover over a large area can be achieved by satellite image processing in a very short time, providing complete, reliable and very economical area statistics, although the lack of enough qualified personnel to manage the remotely-sensed imagery could be a drawback. Moreover, the interpretation of remote-sensing images at several dates in the year will obviously improve/complete cropping system classification and agro-environmental assessment. For example, an image taken in late summer in the Mediterranean region would make it possible to distinguish between spring-sown crops such as sunflower and vineyards, which were not possible to assess by automatic image processing in early summer.

A follow-up of soil management is essential for the assessment of agro-environmental measures. For example, the presence of crop stubble and of cover crops in orchards is an indicator of no-tillage, soil erosion control, the prevention of superfluous carbon dioxide emissions and of a high soil living-organism biodiversity (García-Torres, 2001). Analysing the same region/area in consecutive years could also identify the crop rotation sequences in any specific farm, which is a key point in the implementation of eco-compliance and environmental measures in the European Union. Diverse crop rotations increase soil fertility and decrease weed, insect- and pathogen-pest pressure. The classification/assessment procedure herein described can also be useful as a preliminary work for the assessment of soil erosion and water quality over an entire watershed and of soil organic matter evolution or carbon credits over large areas. One conflicting aspect about this technology could be the acceptance of the results in the case of evidence that a farmer has violated the agro-environmental regulations. This methodology and the results can be used as a tool to help and orient the administrative follow-up, but less as a legal proof of the breach. In that case, inspectors of the administration should visit the accused farm in order to take a most evident report (i.e., with on the ground photographs and proofs).

Reflectance of most land covers studied generally show a consistent stability during the summer season (data not published), due to the fact that either they are desiccated, such as the cover crops between olive trees, crop stubble and herbaceous crops, or they are perennial trees, such as olive trees and roadside trees or they are inert covers, such as bare soil, highways and burnt covers (López-Granados, pers. comm.). This makes the calendar for satellite image-taking flexible in this season. Another additional positive feature for using these remote-sensing techniques in the Mediterranean region is the 
high probability of cloud absence throughout the summer season. Therefore, this methodology could be adapted and extrapolated to other areas around the world with similar Mediterranean climate, crops and cropping systems.

\section{CONCLUSION}

The most important land covers and agro-environmental measures required in the Mediterranean dryland area can be discriminated, classified and quantified through the processing of a QuickBird image taken in early summer, with an overall accuracy of around $90 \%$. The described methodology provides an easy tool for assessing cropping system area statistics and checking on some administrative requirements established by the European Union agrarian policy. This procedure could be adopted by national and regional administrations in the Mediterranean area, making it feasible to substitute most, if not all, ground visits and visual assessments. Once the knowhow of image processing is defined for each agricultural area, automatic procedures to discriminate land covers can be set up, which will save even more time. Furthermore, permanent quantitative records can be obtained, which support tentative claims from farmers. Also, the same image analysis procedure can be implemented only on any specific farm or single plot, and could help farmers and technicians to make decisions about the management of sustainable agricultural practices.

Acknowledgements: This research was partially funded by the Spanish Ministry of Education and Science (MEC) by R+D Projects AGL200760926/AGR and AGL2005-06180-CO3-02. The research of Dr. M. JuradoExpósito was supported by the MEC-Ramón y Cajal Programme.

\section{REFERENCES}

Anonymous (2003) Regulation of the European Council 1782/2003: Establishing common rules for direct support schemes under the common agricultural policy and establishing certain support schemes for farmers, and on the common organisation of the market in olive oil and table olives and amending Regulation (EEC) No. 827/68, Off. J. Eur. Union 270, 1-69.

Anonymous (2004) Real Decreto 2352/2004, sobre la aplicación de la condicionalidad en la aplicación de las ayudas directas en el marco de la política agraria común, Ministerio de Agricultura, Pesca y Alimentación, Spanish Official Bulletin (BOE) 24 de diciembre, 41690-41698.

Anderson G.L., Everitt J.H., Richardson A.J., Escobar D.E. (1993) Using satellite data to map false broomweed (Ericameria austrotexana) infestations on south Texas Rangelands, Weed Sci. 7, 865-871.

Baatz M., Schäpe A. (1999) Object-oriented and multi-scale image analysis in semantic networks, Proceedings of the 2nd international symposium on operationalization of remote sensing, Enschede: ITC, pp. 16-20.

Calera A., González-Piqueras J., Meliá J. (2002) Remote sensing monitoring crop growth, Proceedings of the 1st international symposium on recent advances in quantitative remote sensing, Valencia, pp. 522-529.

Casady G.M., Hanley R.R., Seelan S.K. (2005) Detection of leafy spurge (Euphorbia esula) using multidate high-resolution satellite imagery, Weed Tech. 19, 462-467.

Chuvieco E., Martín M.P., Palacios A. (2002) Assessment of different spectral indices in the red-near-infrared spectral domain for burned land discrimination, Int. J. Remote Sens. 23, 5103-5110.
Elmore A.J., Mustard J.F., Manning S.J., Lobell D.B. (2000) Quantifying vegetation change in semiarid environments: precision and accuracy of spectral mixture analysis and the normalized difference vegetation index, Remote Sens. Environ. 73, 87-102.

Everingham Y.L., Lowe K.H., Donald D.A., Coomans D.H., Markley J. (2007) Advanced satellite imagery to classify sugarcane crop characteristics, Agron. Sustain. Dev. 27, 111-117.

Felton W.L., Alston C.L., Haigh M., Nash G., Wicks G.A., Hanson E. (2002) Using reflectance sensors in agronomy and weed science, Weed Technol. 16, 520-527.

Flowers M., Weisz R., Heiniger R. (2001) Remote sensing of winter wheat tiller density for early nitrogen application decisions, Agron. J. 93, 83-789.

García Torres L. (2001) Agricultura de conservación en el olivar: Cubiertas Vegetales, Asociación Española de Agricultura de Conservación / Suelos Vivos, Córdoba, España, 36 p.

Huete A.R. (1988) A soil-adjusted vegetation index (SAVI), Remote Sens. Environ. 25, 295-309.

Huete A., Justice C., Liu H. (1994) Development of vegetation and soil indices for MODIS-EOS, Remote Sens. Environ. 49, 224-234.

Jackson R.D., Huete A.R. (1991) Interpreting vegetation indices, Prev. Vet. Med. 11, 185-200.

Jordan C.F. (1969) Derivation of leaf area index from quality of light on the forest floor, Ecology 50, 663-666.

Keuchel J., Naumann S., Heiler M., Siegmund A. (2003) Automatic land cover analysis for Tenerife by supervised classification using remotely sensed data, Remote Sens. Environ. 86, 530-541.

Lamb D.V., Weedon M. (1998) Evaluating accuracy of mapping weeds in fallow fields using airborne imaging: Panicum effusum in oil-seed rape stubble, Weed Res. 38, 443-451.

Landis J.R., Kock G.G. (1977) The measurement of observer agreement for categorical Data, Biometrics 33, 159-174.

Martín de Santa Olalla F., Calera A., Domínguez A. (2003) Monitoring water use by combining irrigation advisory service and remotely sensed data with geographic information system, Agr. Water Manage. 61, 111-124.

Mckoy R.M. (2005) Field methods in remote sensing, The Guilford Press, New York, $159 \mathrm{p}$.

Oetter D.R., Cohen W.B., Berterretche M., Maiersperger T.K., Kennedy R.E. (2000) Land cover mapping in an agricultural setting using multiseasonal Thematic Mapper data, Remote Sens. Environ. 76, $139-155$.

Peña-Barragán J.M., López-Granados F., Atenciano S., Jurado-Exposito M., Sánchez de la Orden M., García-Ferrer A., García-Torres L. (2004) Assessment of soil uses in olive groves from aerial photographs, Agr. Ecosyst. Environ. 103, 117-122.

Rouse J.W., Hass R.H., Schell J.A., Deering D.W. (1973) Monitoring vegetation systems in the Great Plains with ERTS, in: RJW and RS (Eds.), Proceedings of the Earth Resources Technology Satellite Symposium NASA, SP-351, 1, pp. 309-317.

South S., Qi J., Lusch D.L. (2004) Optimal classification methods for mapping agricultural tillage practices, Remote Sens. Environ. 91, 90-97.

Stehman S.V., Czaplewski R.L. (1998) Design and analysis for thematic map accuracy assessment: fundamental principles, Remote Sens. Environ. 64, 331-334.

Thorp K.R., Tian L.F. (2004) A review of remote sensing of weeds in agriculture, Precis. Agr. 5, 477-508.

Thomlison J.R., Bolstad P.V., Cohen W.B. (1999) Coordinating methodologies for scaling landcover classifications from site-specific to global: steps toward validating global map product, Remote Sens. Environ. 70, 16-28.

Underwood E., Ustin S., DiPietro D. (2003) Mapping nonnative plants using hyperspectral imagery, Remote Sens. Environ. 86, 150-161. 